\author{
Abstracta Iranica \\ Abstracta Iranica Revue bibliographique pour le domaine irano-aryen \\ Volume 42-43 | 2021 \\ Comptes rendus des publications de 2019-2020
}

\title{
Meysam Labbaf-Khaniki. "Trial Trenching and Discovery of a Columned Building in Bazeh-Hur (North-East Iran)"
}

\section{Barbara Kaim}

\section{(2) OpenEdition \\ Journals}

Édition électronique

URL : https://journals.openedition.org/abstractairanica/51813

DOI : 10.4000/abstractairanica. 51813

ISSN : 1961-960X

Éditeur :

CNRS (UMR 7528 Mondes iraniens et indiens), Éditions de l'IFRI

\section{Référence électronique}

Barbara Kaim, " Meysam Labbaf-Khaniki. "Trial Trenching and Discovery of a Columned Building in Bazeh-Hur (North-East Iran)" ", Abstracta Iranica [En ligne], Volume 42-43 | 2021, document 5, mis en ligne le 30 décembre 2020, consulté le 25 décembre 2022. URL : http://journals.openedition.org/ abstractairanica/51813; DOI : https://doi.org/10.4000/abstractairanica.51813

Ce document a été généré automatiquement le 25 décembre 2022.

Tous droits réservés 


\title{
Meysam Labbaf-Khaniki. “Trial Trenching and Discovery of a Columned Building in Bazeh-Hur (North-East Iran)"
}

\author{
Barbara Kaim
}

\section{RÉFÉRENCE}

Meysam Labbaf-Khaniki. “Trial Trenching and Discovery of a Columned Building in Bazeh-Hur (North-East Iran)”, Iran 58 (2), 2019, p. 221-235

1 Le čahārțāq de Bazeh-Hur est un des rares monuments de cette espèce connus aujourd'hui dans le nord-est de l'Iran. H.G. Bellew (1874) \& Ernst Diez (1923) ont été les premiers à l'identifier comme un temple du feu sassanide. Cependant, à ce jour, il n'y a eu pas de preuve définitive à l'appui de cette idée. Que le čahārțāq n'était pas un bâtiment isolé cela était déjà visible sur les plans publiés par E. Herzfeld ("Damascus: studies in architecture", Ars Islamica, 9, 1942, p. 1-53); U. Hallier ("Ribat-i Sefid, (Khorasan)", AMI, 8, 1975, p. 143-65) et W.Kleiss ("Kuppel- und Rundbauten aus sasanidischer und islamischer Zeit in Iran", AMI, 11, 1978, p.151-166). Les nouvelles fouilles menées sur le site par l'A ont révélé une salle à colonnes adossée à la façade Est du čahārțāq, un ensemble bien connu dans l'architecture résidentielle et religieuse depuis la période moyenne sassanide. Il faut attendre les résultats des prochaines saisons de fouilles qui pourront répondre à la question de savoir si l'ensemble architectural de Bazeh-Hur était-il une résidence palatiale ou un temple du feu. 


\section{AUTEURS}

BARBARA KAIM

Université de Varsovie 